We there look in rain for a muscular cord similar to that which we so easily perceive in animals, elevating the thin and transparent peritoneum, and running along parallel to the ovarian vessels. Nothing has ever been described, nor, perchance, even ever found analogous to it in the human female. The only difference which in reality there is, however, is that in this case the muscular fibres, instead of being condensed into bands, are spread out into a membrane; and instead of going separately for the length of the vascular cord, they cross it, envelope it, mount with it towards the lumbar region, and gradually become lost in the fascia propria, by means of which they are fixed to the posterior parictes of the trunk.

The existence of these fascia being determined, if we now seek to follow their course and their connections, we see that a certain number of them radiate upon the posterior layer of the great ligament, and go in front towards the uterus; that others, raising the peritoncum in the form of a fold, are reflected off towards the top of the ovary and fix themselves to the fimbriated extremity, whilst the greater number, accompanying the vessels as far as the umbilicus of the ovary, a part seem to penetrate the parenchyma of the gland, and a part, crossing the crectile bulb and continuing their way to the extremity of the tube, appear to lose themselves in the contractile envelope of this canal. In the last part of their course, these fibres intersect with those which come from the ligament of the ovary.

[To be continued.]

\title{
PASSAGE OF A LARGE STONE THROUGH THE URETHRA OF A BOY TWO YEARS OLD.
}

\section{Reported by W. M. Turner, M.D., of Petersburg, Va.}

ON the night of the 29 th ult., I was sent for to sec a boy who, the woman told me, was suffering from retention of urine. The case was under the treatment of Dr. Weldon Claiborne, of this city, and the woman who called me brought a request from Dr. C. to carry a catheter with me and endeavor to get away the uriue; he, the Doctor, being compelled to go into the country before returning to his office, and he had, unfortunately, no catheter with him. I went, and found for my patient a handsome little boy (colored), about 27 months old. He was lying on his back, moaning most piteously-his countenance betraying acute suffering. 'The pulse was both frequent and quick, ranging in beats to the minute from 125 to 135 . Before proceeding to explore the region of the bladder, I was led to examine the chest by the circumstance of accidentally placing my hand over the right lung, and feeling a decided vibratory thrill. Applying my ear for auscultating purposes, I detected a pneumonia in the upper lobes of both lungs, 
and in the second stage; as bronchial respiration and bronchophony were well marked, as well as was dulness on percussion. Upon inquiry, I learned that the child had been sick a month previous, with measles, and, having taken cold when recovering, had been complaining more or less ever since that time.

The bladder, to which I then turned my attention, was cnormously distended, protruding and hanging over the pubic arch, somewhat resembling, in miniature, the "pendulous-belly" of pregnant women. The cpidermis of the abdomen, over the bladder, was quite red and shining, and I was indeed fearful of an artificial opening. The penis was much enlarged, and apparently infiltrated with urine. This, however, was not the case, as subsequent examination proved. To add to the difficulties of the case, there was present a congenital pliymosis-rendered ten times more rigid in its contraction by the swollen state of the penis. It was a difficult task, which I then set to work to accomplish-that of drawing off the urine of a boy 27 months old, under circumstances of such pain to the little paticnt, and of such disadvantage to myself. The swollen and phymosed condition of the penis, and the great irritability of the clild, rendered it almost impossible even to make an attempt with the cathcter. At the slightest touch the boy would shrick and scream, until I actually thought the strained bladder would rupture before the prolonged muscular contraction would relax. Finally, after much patience and considerable manœuvring, my only assistant being an old lady, who managed to hold the child's hands, I succeeded in passing a small gum catheter through the hard, pursed-up, phymosed ring, and, as fortune would have it, into the urethra. This feut I was compelled to perform several times, for the frantic efforts of the child dislodged the catheter, and my labor was thrown away. However, I placed my knee upon the lower extremities of the child, and in this position succeeded in passing the instrument once more into the urethra. Moving it slowly and cautiously downward, I soon had the satisfaction of reaching the bladder, which I knew to be the case by the sudden gush of the pent-up urine through the catheter. At the neck of the bladder, I noticed a slight gritty feel as the catheter glided along; it was transient, however, and I thought nothing of it, attributing it to the ring of a cartilaginous stricture, which I had no doubt existed. The boy was instantly relieved, and fell asleep while the urine-an enormous quantitywas flowing. I prescribed nothing for the patient that night, except cold cloths around the penis. The next morning, the first of August, I saw the boy with Dr. Claiborne; we found the patient much refreshed and considerably improved by a good night's rest. The belly, over the region of the bladder, had lost the prominent bullety appearance of the previous evening, and appeared more natural, yet it was still very tender. The penis possessed yet its infiltrated look, and resembled much a transparent gelatinous subVoL. LXIII. $-9 * *$ 
stance-differing only in a solid appearance. We found that the boy had already passed his urine once, but in a very unsatisfactory manner, screaming at the top of his voice when the urine reached the urethral canal, and refusing most positively to make further effort. The result was, when we arrived, he was again unable to urinate. Once more my little gum catheter was called into requisition, and our united efforts bad the desired effect of bringing away the urine. As I had a case of instruments with me, Dr. C. advised operation for phymosis; suggesting that, perhaps, the rigidity with which it fastened around the glans penis prevented micturition. We divided the pressure with a bistoury and director. The operation was over in a few minutes. After splitting the prepuce, we discovered that the retention of the urine could not have been due to the pressure made over the mouth of the urethra by the phymosis. When I passed the catheter in to empty the bladder, I detected, very plainly, the same gritty feel which I had remarked the cvening previous. Dr. Claiborne was equally sensible of the peculiar sensation. The touch was decisive; there could be no mistaking the fact of the presence of a foreign body. Dr. Claiborne immediately pronounced the case to be stone. In withdrawing the catheter, which I had used as a sound, I distinctly felt an opposing substance. Dr. C. at this moment remarked, that he distinctly felt, between his thumb and forefinger, a round or irregularly round tubercle in the urethra. After several introductions of the catheter, I finally succeeded in hooking the stone in the fenestra of the instrument, and, with a sudden motion, drew it forward an inch toward the external orifice of the meatus urinarius. Here we experienced much difficulty in our work; we dared not split the urethra; and yet it was very difficult to obtain a hold on the stone, which showed a constant tendency to retrocede. Finally, after much patience and manipulation, we obtained a fastening on the stone with a pair of dressing forceps, and extracted it. The boy came near swooning, but soon revived. The following are the dimensions of the stone: Length five eighths, and circumference three-quarters of an inch; weight, nearly forty-two grains; shape, semi-conoidal and semi-cylindrical-the presenting end corresponding to the apex of the cone. An analysis of the stone proved it to be oxalate of lime.

A further examination, using the catheter as a sound, revealed, as we had already suspected, the presence of another calculus in the bladder, and we came to the conclusion that the lithogenesis was hereditary. On inquiry, however, I learned nothing which would warrant the supposition. The boy has not suffered, especially since the time of the passage of the stone. He is now running about, and seems to be lively enough. That he will be troubled again with calculus, there can be no reasonable doubt; how soon first, I cannot say.

The noticeable feature in this case is, that a stone of such a size 
did pass through the urethra of a child two ycars of agc.-Maryland and Virginia Medical Journal.

\section{IReports of Ftedical Societies.}

EXTRACTS FROM THE RECORDS OF TIIE BOSTON SOCIETY FOR MEDICAL IMPROVEMENT. BY FRANCIS MINOT, M.D., SECRETARY.

JULY 23d.-Perkins's Traclors.-Dr. J JCKson exhibited a pair of "Perkins's Tractors," that were so famous, about the commencement of the present century, for the cure of almost every sort of disease, and that imposed upon the credulity of all classes for several years, in Europe as well as in this country. They were sent to Dr. J. for the Museum of the Medical College, by Dr. Jonathan Ware, of Milton, and may be compared, in form, to a stilet about three inches in length, that has been cut longitudinally into two equal parts ; one is of brass and the other of steel; one surface is convex and the other flat; one extremity is large and rounded, and from this it tapers off to a sharp point, the greatest width upon the flat surface being one-fourth of an inch. With the tractors, Dr. W. sent a short biographical sketch of Dr. Perkins, with some account of his discovery, the details of which may be found in Thacher's IIedical Biography, and in the Encyclopcedia Americana.

$\Lambda$ Ug. 13th.-Cancerous Disease of the Bladder.-Dr. JAckson showed the specimen, which he had received from Dr. J. H. Blake, of North $\Delta$ uburn, Me. It had been in weak spirit, but the appearances, excepting the color, were well preserved. The cavity of the organ was smaller than natural ; parietes much thickened and indurated, and had a scirrhous look; extensive ulceration of the inner surface, ill-defined towards the fundus, but separated by a high margin from the adjacent mucous membrane towards the neck of the bladder. This last membrane was irregular upon its surface, and had what would be generally called a "thickened, fungoid look" and feel. The prostate gland was healthy. The bladder contained, arcording to Dr. B.'s report, about an ounce of reddish-gray, slimy, grumous liquid; and a small quantity of the same was found in the ureters and in the kidneys, having been forced up from the bladder. The ureters and pelres of the kidneys were dilated; but otherwise, the organs were healthy.

The following is essentially the history of the case, as it was sent by Dr. B. The patient was a farmer, 68 years of age, of good constitution and habits, but always very anxious about himself when he was not perfectly well, and always looking forwards to a suffering old age and painful death. Since October, 1858, he has had occasional hæmaturia, and of late this had been constant. At first, the blood was generally diffused in the urine, but sometimes it came away in clots which were often large, and passed with difficulty. During the last three months he passed a large quantity of solid substance, looking like partially organized fibrin or pieces of placenta that had been retained for a day or two. These coagula never looked as if they came through the ureters: and there never appeared to be any renal difficulty.

When his disease cominenced, he became desponding, and manifested the greatest distress of mind, although he said that he had no pain, 